\title{
A REPRESENTAÇÃO \\ DA VERDADE PELO DISCURSO CIENTÍFICO: VISTAS A UMA RUPTURA DE PARADIGMAS DO LETRAMENTO ACADÊMICO
}

\author{
LA REPRESENTACIÓN DE LA VERDAD POR EL DISCURSO CIENTÍFICO: HACIA UNA \\ ROTURA DE PARADIGMAS DEL LETRAMIENTO ACADÉMICO
}

THE REPRESENTATION OF TRUTH BY THE SCIENTIFIC DISCOURSE: VIEWS TO A RUPTURE OF THE ACADEMIC LITERACY PARADIGMS

Paulo Gerson Stefanello *

Universidade Federal de São Carlos

RESUMO: Este artigo versa, a partir de uma perspectiva teórica, sobre a questão da escrita na esfera acadêmica. As particularidades dos modos de leitura e escrita nessa esfera constituem um mundo de letramentos caracterizado por uma formalidade que o distingue, propositalmente, de outras situações de uso dessas habilidades. A apropriação e a manutenção do discurso científico, no entanto, requerem do alunado competências usualmente pouco desenvolvidas ao longo de seus anos na educação básica e que realçam as dificuldades enfrentadas, tanto pelo aluno como pelo professor, na transição para o ensino superior. Para a corrente discussão, amparo-me nos estudos de letramento (STREET, 1984, 2003; KLEIMAN, 1995; HAMILTON, 2002) para tratar, especificamente, do letramento acadêmico e do regime de verdade (FOUCAULT, 2004) através do qual se legitima o discurso científico na sociedade.

PALAVRAS-CHAVE: Discurso científico. Letramento acadêmico. Modelo ideológico de letramento. Regime de verdade.

RESUMEN: Este artículo versa, desde una perspectiva teórica, sobre el tema de la escritura en el ámbito académico. Las particularidades de los modos de lectura y escritura en esta esfera son un mundo de letramientos que se caracterizan por una formalidad que lo distingue a propósito de otras situaciones de uso de estas habilidades. La propiedad y el mantenimiento del discurso científico, sin embargo, requieren habilidades de los estudiantes por lo general poco desarrolladas a lo largo de sus años en la enseñanza básica y ponen de relieve las dificultades que tienen tanto el alumno como el profesor, en la transición a la educación superior. Para la discusión actual, me apoyan los estudios de letramiento (STREET, 1984, 2003; KLEIMAN, 1995; HAMILTON, 2002) para abordar específicamente el letramiento académico y el régimen de verdad (FOUCAULT, 2004) a través del cual el discurso científico está legitimado en la sociedad.

PALABRAS CLAVE: Discurso científico. Letramiento académico. Modelo ideológico de letramiento. Régimen de verdad.

* Doutorando em Linguística pelo Programa de Pós-graduação em Linguística da Universidade Federal de São Carlos (UFSCar). Mestreelicenciadoem Letras. E-mail: pgrstefanello_@hotmail.com. 
ABSTRACT: This article discusses, from a theoretical perspective, the question of writing in the academic sphere. The particularities of the ways to read and write in this sphere constitute a world of literacies characterized by a formality that distinguishes it, purposely, from other use situations of these abilities. The appropriation and maintenance of the scientific discourse, however, require students' competences commonly not well developed during the years in basic education and which highlight the difficulties faced by both the student and the teacher in the transition to higher education. For the current discussion, I rely on literacy studies (STREET, 1984, 2003; KLEIMAN, 1995; HAMILTON, 2002) to deal, specifically, with academic literacy and the truth regime (FOUCAULT, 2004) through which the scientific discourse is legitimated in society.

KEYWORDS: Scientific discourse. Academic literacy. Ideological model of literacy. Truth regime.

\section{INTRODUÇÃOO}

A ciência constitui-se como tal através de uma discursivização e de um aparato técnico específicos, que visam ao rompimento da leitura de senso comum do real. A linguagem que dá corpo a um estudo acadêmico-científico consiste em um padrão de uso da língua que, ademais de rigoroso e estético, deve ser objetivo na apresentação de uma investigação e/ou na proposição de reflexões que precisam de existência num dado contexto.

Santos (1989) chama a atenção para a necessidade de ir para além das evidências simples e de códigos primários de leitura para visualizar um problema a partir de outra perspectiva, e esse parecer pode ser trazido, inclusive, para dentro das universidades, quando alunos dos mais distintos cursos discutem o que é e o que não é ciência, ou quando professores das mais distintas áreas do conhecimento também o fazem, como se fosse possível acomodar a ciência numa caixa arquitetonicamente impecável, com encaixes perfeitamente simétricos e sem rebarbas, olvidando-se (justamente no meio em que isso não deveria ocorrer) de que o objetivo de um estudo científico não deve trazer exclusivamente verdades e definições novas, mas novas formas de relacionar as que já existem, para que, em algum momento, venha a ser possível a emergência de um novo conceito ou de uma nova compreensão acerca de uma informação.

De toda maneira, essas relações e proposições requerem certa padronização e a escrita pela qual se propagarão tem fundamental importância, não no que se refere à escolha da língua nacional, mas em relação a uma articulação universal que ampara o texto técnico e que foi herdada da filosofia quando, num tempo em que se considerava uma grande distinção desta com a ciência, seu caráter hegemônico era muito mais visível do que nos dias atuais.

Pereira (2013, p. 217) faz menção a Schopenhauer quando afirma que, no tempo do pensador, o objetivo maior da filosofia, “[...] quando postulava a ideia de pensar por si mesmo, estava ancorado no exercício filosófico e na reflexão, apropriando-se e dominando o próprio saber [...]", e que a ciência "[...] representava ainda antes um efeito da combinação de discursos preexistentes [...]". Enquanto a filosofia se permitia falar em primeira pessoa, a ciência utilizava-se de impessoalidade ou de universalidade, de modo que não visibilizasse seu enunciador, garantindo um efeito neutro à resistência e à validação daquilo que se quer afirmar como verdade. "Atravessamos o século XIX pensando que $a$ verdade era $u m a$ verdade. No século XX, alcançamos ver que $a$ razão era $u m a$ forma de racionalidade e que o homem não tem nenhuma essência que o preceda [...]” (PEREIRA, 2013, p. 221, grifos do autor).

Sob essa luz, cada verdade se torna a expressão de mecanismos de poder de quem a propõe, fazendo-o na intenção de controlar a origem de seu discurso, embora essa origem repouse nas formações discursivas construídas ao longo da história e dentro das quais está inscrito. Contudo, não se deve esquecer de que a própria determinação do sentido de verdade é o resultado de um processo coercitivo que se desenvolve na sociedade e que dela depende. "Cada sociedade tem seu regime de verdade, sua 'política geral' de verdade; isto é, os tipos de discurso que ela acolhe e faz funcionar como verdadeiros [...]” (FOUCAULT, 2004, p. 12), com base em memórias que acessam o já-dito, autorizando certos sentidos atribuídos às palavras e desautorizando outros.

Importa realçar aqui a relação que Cloran (2000) propõe entre os significados que são revelados pelo autor de um texto através de suas experiências no mundo; os mecanismos linguísticos que viabilizam esses processos de significação e o contexto em que se 
inserem ambos, o sujeito e suas experiências. A posição ocupada pelo sujeito do fazer numa comunidade linguística específica é o que sustenta tal relação, que materializa o fazer pelo projeto dizer desse sujeito.

Nesse sentido, as próximas seções propõem alcançar uma relação entre as experiências de mundo e as práticas letradas refletidas no fazer social, isto é, nos mecanismos de escrita responsáveis pela caracterização social da identidade, sobretudo no âmbito acadêmico, tendo em vista o propósito de compreender este processo e embasar discussões temáticas concernentes aos Estudos do Letramento e que contemplam, mais especificamente, a importância do letramento acadêmico na sociedade.

\section{ACERCA DOS LETRAMENTOS}

A noção de letramento começou a ser utilizada no Brasil durante a década de 1980 e foi-se amadurecendo ao passo que frutificavam as discussões advindas de literacy, em inglês, que carregava certo equívoco no uso em português ao associar letramento ao conceito de alfabetização.

Kleiman (1995), embasando-se nos trabalhos seminais de Brian Street (1984) e de Hamilton junto com Barton e Ivanic (1993), promove uma "[...] tentativa de separar os estudos sobre o 'impacto social da escrita' dos estudos sobre a alfabetização, cujas conotações escolares destacam as competências individuais no uso e na prática da escrita [...]" (KLEIMAN, 1995, p. 15), o que passou a ser denominado como modelo autônomo, uma vez que não se considera a influência do contexto sobre a realização das práticas.

Street (2003, p. 77) realça que os Estudos do Letramento representam uma visão do letramento que ao invés de focalizar a aquisição de habilidades, como se faz dentro das abordagens tradicionais, é uma prática social, de forma a existirem múltiplos letramentos passíveis de variação no tempo e no espaço de acordo com as relações de poder que configuram essas práticas.

Em linha semelhante de pensamento, Oliveira (2008, p.114) propõe que olhar para o fenômeno do letramento

[...] como uma prática social implica compreender que as ações de linguagem são produzidas e interpretadas por um sujeito cognoscitivo, mas também clivado pelas interferências do mundo vivido a partir do qual ele constrói representações, crenças, sentimentos, formas de regulação social e a si mesmo. Não há, assim, letramento deslocado do sujeito que o produz e do contexto que o circunda.

Hamilton (2002, p. 8) trabalha sob o prisma do desprestígio e da desvalorização que se atribui a muitos tipos letramentos, não considerados socialmente válidos ou institucionalizados, ignorando quaisquer experiências de letramento que não estejam descritas em documentos comprobatórios. Em sua reflexão, a autora contrapõe os letramentos hegemônicos que classifica como "institucionalizados", fomentados, por exemplo, pela escola, pelas igrejas, pelo local de trabalho, pelo sistema legal, pelo comércio, aos letramentos locais “vernaculares”, que não são, por sua vez, regulados por instituições, mas que surgem na vida cotidiana, no âmbito das culturas locais (HAMILTON, 2002, p. 4). Ser letrado, não é "[...] simplesmente uma questão cognitiva, mas simultaneamente envolve outros modos de se engajar no mundo" (HAMILTON, 2002, p. 183).

A quase inevitabilidade de adesão a esse modelo ideológico de letramento também é discutida por Marcuschi (2001), haja vista que na atual conjuntura social a perspectiva crítica $^{1}$ tem essencial importância no trabalho com práticas de leitura e de escrita, junto com uma abordagem etnograficamente situada e com a culturalidade que é parte dos domínios discursivos de um indivíduo social. Entretanto, o estudioso lida com esse entendimento sob certa cautela, não tratando o letramento com uma questão exclusivamente social e política. Seu modelo ideológico ideal à luz do letramento seria

\footnotetext{
${ }^{1}$ Tal perspectiva comunga da criticidade postulada na Análise Crítica de Discurso, proposta por Fairclough (1989, p. 20), que propõe uma concepção de “[...] linguagem como uma forma de prática social $[\ldots] "$.
} 
[...] o que parte da observação das relações entre a oralidade e o letramento na perspectiva do contínuo das práticas sociais e atividades comunicativas, envolvendo parcialmente o modelo ideológico (em especial o aspecto da inserção da fala e da escrita no contexto da cultura e da vida social) e observando a organização das formas linguísticas no contínuo dos gêneros textuais [...] (MARCUSCHI, 2001, p. 4).

Existe uma posição de centralidade no entendimento de Marcuschi. Ao passo que ele busca distanciar-se do modelo autônomo, busca, também, não aproximar-se do extremo do modelo ideológico. Enquanto as questões linguísticas devem estar vinculadas aos contextos social, cultural, político, entre outros, o estudioso chama atenção para um caminho de dissociação da preocupação com a linguagem no caso de a perspectiva ideológica de letramento ser embasada majoritariamente em seus contextos de uso, de forma que denotaria a preocupação de um cientista social, ou político, por exemplo, ao invés de um cientista da linguagem.

Sobre esse mesmo modelo de letramento, Kleiman (1995, p. 21, grifos meus) determina a não existência de "[...] uma relação causal entre letramento e progresso ou civilização ${ }^{2}$, ou modernidade, pois, ao invés de divisor entre grupos orais e letrados, ele pressupõe a existência, e investiga as características, de grandes áreas de interface entre práticas orais e práticas letradas [...]”.

Esse caráter deve-se, justamente, pela compreensão de que “[...] as práticas de letramento, no plural, são social e culturalmente determinadas e, como tal, os significados específicos que a escrita assume para um grupo social dependem dos contextos e instituições em que ela foi adquirida [...]" (KLEIMAN, 1995, p. 21).

Assim, as chamadas práticas de letramento são, na verdade, práticas discursivas que determinam a produção e a interpretação de textos dentro de determinados contextos, ou seja, há uma relação de interdependência entre contexto e práticas, de modo que estas últimas, uma vez que se materializam conforme o contexto de uso, são constituídas ideologicamente e, consequentemente, não são neutras. Desse modo, não se deve enxergar os discentes como membros vazios e não pertencentes a uma sociedade, uma vez que suas experiências de vida são compostas de uma série de eventos de letramento que emanam processos de significação a serem manifestados em momento devido e oportuno.

Congruentes às práticas de letramentos, os eventos de letramento, noção cunhada por Heath (1983), correspondem a qualquer situação de envolvimento entre um ou mais indivíduos com as práticas de leitura e escrita, possibilitando a eles que integrem a natureza das interações entre os participantes e a interpretação delas, tomando o texto, portanto, como objeto mediador da interação.

No âmbito dos eventos e práticas, em que um fenômeno só se permite ocorrer e produzir significação a partir do outro, faz-se necessário atentar para outra noção trazida por Barton (1994), que me parece bastante coerente para tratar, em seguida, sobre o letramento acadêmico, em específico, que é a de mundos de letramento. Para esse autor, bem como para outros já referidos há pouco, as práticas de letramento mantêm-se atreladas ao contexto sociocultural em que ocorrem. Dessa maneira, isto permite afirmar que cada grupo social participa de mundos exclusivos de letramentos, pois as experiências por que passa são naturalmente distintas e diferentemente significativas.

A esse respeito, Dantas (2012, p. 44-45) assevera:

[...] o papel dos espaços sociais e das interações sociais que neles ocorrem de modo que podemos entendê-lo como o palco de representações para as múltiplas práticas sociais, observando que o papel desempenhado pela escrita e pela leitura assume um caráter estruturante. No entanto, é preciso atentar para o fato de que leitura e escrita não circulam da mesma forma em todos os contextos sociais. A contribuição de textos obedecerá necessariamente às necessidades comunicativas de uma comunidade ou de grupos de pessoas, revelando quais textos e quais práticas constituem os mundos de letramento desses grupos.

\footnotetext{
${ }^{2}$ O letramento é hoje compreendido como um conjunto de práticas sociais de alguma forma atreladas à escrita em contextos específicos e com propósitos específicos Nesse sentido, não deve haver uma ideia de progresso dependente de práticas escolares, por exemplo, haja vista que a escola, pensada como instituição, contempla apenas algumas habilidades situadas (KLEIMAN, 1995; SIGNORINI, 1995; STREET, 1984, entre outros).
} 
Também, em artigo que discute sobre os mundos de letramento em pesquisa realizada por Tinoco (2008, p. 64) com professores do agreste do Rio Grande do Norte, e que integra a obra Letramentos múltiplos: agentes, práticas, representações, organizada por Kleiman e Oliveira, o referido autor realça:

Ao focalizar suas práticas de leituras e escritas, deparamo-nos com um ambiente multicultural bastante complexo: diferentes experiências de leitura e de escrita determinadas por diferentes instituições, cada qual com suas experiências, expectativas e objetivos específicos. Para o reconhecimento das especificidades dessas experiências, uma atividade que desenvolvemos em nossas pesquisas foi a de mapear as práticas de letramentos dos professores em formação no agreste norte-rio-grandense. Esse mapeamento representa uma tentativa de compreender quem são esses professorandos e quais são os mundos de letramento em que eles estão envolvidos.

Com vistas a sequenciar a discussão aqui alinhavada, dou início à seção que buscará refletir sobre o letramento acadêmico e alguns elementos que constituem esse mundo.

\section{A NÃO-NEUTRALIDADE DO LETRAMENTO ACADÊMICO}

No final da década de 1960 e início da de 1970, nos Estados Unidos, e no final dos anos de 1980 e início dos de 1990, no Reino Unido, ações promovidas pelos respectivos governos levaram à ampliação do acesso às universidades e ao crescimento das comunidades acadêmicas, que passariam a ser compostas por estudantes com as mais diversas origens. As diversidades linguísticas e socioculturais foram bastante acentuadas e denotavam grande heterogeneidade nessas comunidades. Em virtude disso, certa readaptação no ensino da escrita tornou-se necessária.

Nos Estados Unidos, ganhou força o movimento pedagógico Writing Across the Curriculum ${ }^{3}$ (WAC), que defendia a inclusão da escrita nas disciplinas que compunham os currículos universitários. No Reino Unido, a dificuldade e a insuficiência no que se referia à linguagem escrita dos estudantes que iniciavam o ensino superior gerou a crença de que, para a solução do problema, as aulas deveriam ser ministradas com o propósito maior de identificar e efetivamente trabalhar sobre as questões linguístico-textuais (LEA; STREET, 1998).

Conforme argumentei mais no início deste texto, a linguagem científica requer formas mais escolarizadas em relação à linguagem cotidiana, menos formal, sobretudo na escrita. Muito dessa necessidade diz respeito a uma estética que se supõe dever existir num meio de produção e sistematização do conhecimento. O cenário da educação no Brasil, que tem um histórico de desenvolvimento linguístico dos alunos da educação básica a partir do modelo autônomo de letramento, vem passando por um processo de trabalho a fim de reverter as dificuldades que esses alunos apresentam quando ingressam na universidade e precisam se utilizar dessa linguagem mais formalizada Sabemos, entretanto, que esse é um processo extenso, complexo, cujos resultados poderão ser exitosos e adequadamente analisados ao longo dos próximos anos.

Uma vez reconhecido o aspecto situado do texto, fica evidente que o aluno da universidade tenha envolvimento com eventos de letramento, dado que estes representam o contato, propriamente dito, do aluno com textos referentes a sua área de estudo, visando à apropriação de elementos específicos que compõem a esfera acadêmica e, por consequência, a linguagem característica desse mundo de letramento. Trata-se de pertencimento e identidade, fatores por meio dos quais, exclusivamente, terão sentido os textos lidos e produzidos pelo aluno.

O domínio da linguagem técnica é parte importante do aprendizado do cientista... ninguém poderá ser químico, físico ou biólogo sem dominar o jargão de sua área... Mais do que para aos discursos ordinários ou os das ciências humanas, vale certamente para o das ciências exatas a postulação de Pêcheux e Fuchs (1975) de que o significado das palavras e dos enunciados depende do discurso a que pertencem. Repetindo, é nesses discursos, e como consequência de um longo e trabalho histórico, que tais palavras e tais enunciados têm uma leitura unívoca, e

\footnotetext{
${ }^{3}$ Sobre o referido movimento pedagógico e os contextos existentes à época, é interessante a leitura da obra Genre in a changing world, organizada por Charles Bazerman, Adair Bonini e Débora Figueiredo, publicada no ano de 2009, bem como os textos temáticos apresentados na Revista Ilha do Desterro, v. 69, n. 3 (2016).
} 
não em língua portuguesa, inglesa, etc.. Do ponto de vista do treinamento do cientista, parece evidente que ele implica um processo de subjetivação que produz como efeito um assujeitamento às regras do discurso de um grupo institucional [...] (POSSENTI, 1997, p. 20).

O letramento acadêmico, o qual figura como temática central neste artigo, refere-se à habilidade nas competências de ler, escrever, falar e agir dentro dos moldes que caracterizam esse contexto, em específico, sem desconsiderar, entretanto, a influência das experiências sociais, culturais e ideológicas sobre o processo de escrita acadêmica.

Concernente à escrita acadêmica, Lea e Street (1998) apresentam três abordagens que dela tratam: o modelo dos estudos de habilidades, o modelo da socialização acadêmica e o modelo do letramento acadêmico.

O primeiro modelo compreende letramento como as habilidades cognitivas de cada indivíduo do grupo que constitui a academia e que os estudantes precisam adquirir para conseguirem sua inserção nele. A característica de realce desse modelo é o fato de que, uma vez adquiridas essas habilidades, o estudante passaria a utilizá-la de maneira semelhante em outros contextos de escrita.

Sobre o modelo da socialização acadêmica, a inserção na cultura da academia é intermediada pelo professor, sendo este responsável, portanto, pelo processo de apropriação, pelos alunos, das competências mencionadas, através das disciplinas que ministra ou de outros eventos de letramento.

A terceira abordagem focaliza a dimensão dos letramentos que ocorrem na universidade, numa concepção mais ampla, que garantem a multiplicidade das práticas nessa esfera e a decorrente e nova forma de organizar o conhecimento ao qual o estudante passa a ser exposto. É nessa abordagem que o viés social a que venho me referindo é mais bem percebido, pois as trajetórias individuais são determinantes para o processo de apropriação dos elementos da comunidade acadêmica, que não se restringem à escrita, unicamente, mas a todo um rol sobre o qual pairam as relações de poder naquele (neste?) ambiente, o reconhecimento dos discursos mais e menos valorizados e as identidades sociais ali construídas e mantidas. A interposição de práticas orais e escritas torna-se um elemento essencial para a efetivação das práticas sociais do(s) sujeito(s) situadamente contextualizado pela academia.

As práticas sociais e de letramentos, que tanto não devem se confundir quanto não se dissociam, são responsáveis pelo aspecto veridictório de uma proposição, e na medida em que são instrumentalizadas por elementos formais próprios da academia, adquirem caráter de cientificidade, apreendido, sobretudo, por meio da escrita. Com esse gancho, parto para a próxima seção, que versará sobre o regime de verdade que engendra a produção acadêmica, a fim de situar o modo como a verdade pode ser e é representada pelo sujeito de conhecimento.

\section{REGIME DE VERDADE}

Ao tratar a verdade, a preocupação maior de Foucault não está centrada na determinação do que seja ou não verdade, mas nos modos de sua legitimação na sociedade, isto é, nas formas como a sociedade interpreta e determina o que é verdadeiro e o que é falso. Cada sociedade se utiliza de elementos que a caracterizam para essa determinação, de maneira que aquilo que é tomado por verdadeiro por uma composição social pode não ser tomado de mesmo modo por outra.

A isenção de interesses políticos e econômicos num discurso científico também não deve ser vista como pura. Foucault (2004, p. 8) infere que "[...] a verdade está circularmente ligada a sistemas de poder, que a produzem e apoiam, e efeitos de poder que ela induz e que a reproduzem [...]". Os denominados jogos de verdade, que constituem o percurso pelo qual o leitor é guiado e levado a uma determinada compreensão de um fato, são um conjunto de regras, muito delicado, que organiza uma rede de práticas e de instituições coercitivas, dentro da qual se inserem sujeitos que acordam o que pode ou não ser classificado como verdade.

É dentro desta rede de práticas que o discurso científico aparece e é socialmente validado. Ao ocupar essa posição, verifica-se uma dimensão absurdamente ampla e credita-se uma relevância imensurável aos produtores de conhecimento e às universidades, haja 
vista que são os meios de produção de verdades, embora não se possa esquecer que esses meios desenvolvem-se dentro de jogos que possibilitam constituir tanto objetos de conhecimento, como processos de subjetivação dos indivíduos (FOUCAULT, 2004).

O regime de verdade sobre o qual Foucault discute não seria unicamente ideológico, pois o desenvolvimento do capitalismo é concretizado por meio de enunciados científicos e de consequentes mudanças na formação dos enunciados que são tomados por verdadeiros. Somos obrigados a ver quais são os efeitos produzidos no interior dos discursos, fazendo com que sequenciemos uma historicidade a qual chama de belicosa, exatamente por ser construída sob relações de poder e reconhecendo que "[...] o que faz com que o poder se mantenha e que seja aceito é simplesmente que ele não pesa só como uma força que diz não, mas que de fato ele permeia, produz coisas, induz ao prazer, forma saber, produz discurso [...]" (FOUCAULT, 2004, p. 8).

A história do sujeito de conhecimento é o determinante do regime de verdade. Como pode ser observado, Foucault tem, acerca desta temática, uma perspectiva menos marxista e menos naturalística do que a que a escrita acadêmico-científica usualmente admite. Ordinariamente, o discurso científico insiste que um dado estudado, inerentemente inscrito na natureza, seja impresso no sujeito de conhecimento, alimentando a noção de cientificidade e, na mesma direção, a noção de verdade.

Ao passo que se admite que cada verdade possui uma história, sua emergência ao status de verdade deve ser questionada por sua historicidade a partir de um contexto específico de práticas sociais das quais domínios de saber são componentes. O postulado foucaultiano focaliza a descentralização do sujeito como centro do conhecimento, uma vez que esse sujeito de conhecimento é, na verdade, sujeito de representação, sendo por meio dele que o estatuto de verdade emerge.

Assim, Foucault e, posteriormente, Candiotto postulam a favor de duas histórias da verdade. Para o consagrado pensador, uma história interna, que se refere aos princípios que produzem verdade dentro da história da ciência; a segunda, externa, que engloba os vários outros lugares onde a verdade se forma, sendo essa relação existente entre homem e verdade, que é capaz de definir as formas específicas de subjetividades e saberes. Para Candiotto (2007, p. 2), é pertinente que se estabeleça uma distinção entre uma história da verdade daquilo que é e uma história da verdade daquilo que acontece.

Segue a possibilidade de duas histórias da verdade: uma da manifestação daquilo que é: verdade-apofânica, verdade-descoberta, verdade-abstrata, constante, demonstrada e objetiva que faz uso da mediação de instrumentos; outra, da ordem daquilo que acontece, das técnicas de produção, de captação mediante rituais e recusas, efeito de jogos de verdade que ocorrem nas práticas concretas.

É pertinente, portanto, o ressalto de que a produção de conhecimento, respaldada pelo discurso científico formal não ocorra somente dentro das ciências. Caso isto fosse assim tomado, equivaleria a afirmar que todas as formas de contato com outros textos não científicos, na essência, e outras pessoas numa relação dialógica não contribuísse para a formação própria do sujeito. O saber não pode ser atrelado estritamente com a ciência. Esta apenas detém de formalidade e rigorosidade naquilo que propõe. A cientificidade pode integrar as práticas discursivas, mesmo aquelas que não são claramente científicas, mas não as constituem na íntegra.

Os territórios arqueológicos podem atravessar textos 'literários' ou 'filosóficos', bem como textos científicos. O saber não está investido somente em demonstrações, pode estar também em ficções, reflexões, narrativas, regulamentos institucionais, decisões políticas [...]. A prática discursiva não coincide com a elaboração científica a que pode dar lugar; o saber que ela forma não é nem o esboço rigoroso nem o subproduto cotidiano de uma ciência constituída. As ciências - pouco importa no momento a diferença entre os discursos que têm uma presunção ou um estatuto de cientificidade e os que não apresentam realmente seus critérios formais - aparecem no elemento de uma formação discursiva e tendo o saber como fundo (FOUCAULT, 1969, p.222).

Nesse viés, evidencia-se a interferência (embora não me pareça o nome mais adequado) da identidade subjetiva, da ideologia, da carga cultural, das experiências de vida, enfim, dos interesses, como há pouco mencionado, em quaisquer textos produzidos por um indivíduo, inclusive científicos. Coracini (1991, p. 148) já reconhecera que “[...] um texto qualquer resulta do entrecruzamento de uma série de outros textos, de outros autores, outros indivíduos, diferentes grupos ideológicos, enfim de diferentes discursos”, e essa produção é regida por uma historicidade das coisas e dos sujeitos que com elas lidam. 
Esse profícuo panorama, portanto, condiciona o imaginário sobre o regime de verdade que se faz presente nas práticas de letramento acadêmico e na produção científica, habitualmente caracterizada como conhecimento universal. A proposta percorrida neste texto chama a atenção, por fim, para a necessária criticidade ao lidar com textos científicos, a fim de não ignorar a existência de contextos situados que influenciam sua produção, e reduzem, naturalmente, a neutralidade preconizada para o gênero.

\section{CONSIDERAÇÕES FINAIS}

O conhecimento, objeto central da escrita acadêmica, certamente é a temática sobre a qual me amparo para discutir seus meios de disseminação. Costa (2014) sugere que passemos a desenvolver um olhar cada vez mais crítico em relação à concepção de conhecimento que temos defendido no atual contexto sociopolítico brasileiro, buscando verificar em que medida ela é construída ou imposta dentro da universidade. Em primeira instância, é caro reconhecer as ideologias que subjazem às práticas de letramento acadêmico na atualidade, uma vez que, de tão naturalizadas, parecem ter sido amplamente tomadas como verdades absolutas. É claro que a segunda ação seria explicitar tais ideologias aos estudantes e, quando e se necessário, colocar as verdades construídas em xeque.

De modo semelhante a essa posição, pode-se verificar uma tendência que nos é facilmente percebida em conversas cotidianas com pessoas que vão a um médico, por exemplo. A cultura da consulta médica parece ter sofrido grande mudança no modo como a população lida com ela. Há não muitas décadas atrás, conforme relatos que podem, certamente, serem obtidos de pessoas com mais de sessenta anos de idade hoje, a opinião de um único médico sobre dada situação de saúde bastava, por ser tomada como verdadeira, e o eventual tratamento tinha início sem que aquela opinião fosse questionada. Atualmente, é enfática a busca por pareceres médicos distintos, visando a uma confirmação sobre o real estado de saúde de um paciente, isto é, à confirmação da verdade representada.

Essa mesma tendência é o que parece muito tênue, ainda, à universidade e à cultura da escrita acadêmica, mesmo embora tenhamos, e não de hoje, instrumentos para uma ruptura de paradigmas e um cenário favorável para que isso ocorra.

Com a reflexão aqui proposta, ainda que breve, reúno conceitos da Linguística Aplicada, especialmente quando trato a questão da concepção de letramento e do letramento acadêmico, com uma característica mais filosófica acessada pelo discurso científico como representação da verdade, e chamo a atenção para a necessidade de desnaturalização do discurso científico e para seu ponto de partida mais superficial, a escrita acadêmica, à qual, outrora, caberia o estatuto definitivo de verdade.

\section{REFERÊNCIAS}

BARTON, D. Literacy - an introduction to the ecology of written language. Cambridge/USA: Brackwell, 1994.

CANDIOTTO, C. Verdade e diferença no pensamento de Michel Foucault. Kriterion: Revista de Filosofia. Belo Horizonte, v.48, n. 115, p.203-217, 2007.

CLORAN, C. Socio-Semantic variation: different wordings, different meanings. In: UNSWORTH, L. (Ed.). Researching language in schools and communities. Londres, Washington: Cassel, 2000. p. 152-183.

CORACINI, M. J. Um fazer persuasivo: o discurso subjetivo da ciência. S. Paulo: EDUC; Campinas: Pontes, 1991.

COSTA, E. M. Considerações sobre o letramento acadêmico a partir do novo perfil dos graduandos em Letras/Espanhol. In: COlÓQUio INTERNACIONAL CUlTuRA ESCRITA E LETRAMENTO, 5, 2014, Belo Horizonte. Anais... Belo Horizonte, 2014, p. 1-11. 
DANTAS, M. N. Mundos de letramento e agência na construção de identidade de seminarista católicos. Natal/RN: UFRN, 2012.

FAIRCLOUGH, N. Language and power. Harlow: Longman Group UK Limited, 1989.

FOUCAULT, Michel. A arqueologia do saber. Tradução de Luiz Felipe Baeta Neves, revisão de Ligia Vassalo. Petrópolis: Vozes, Lisboa: Centro do Livro Brasileiro, 1972.

Verdade e poder. In: Microfísica do poder. Rio de Janeiro: Edições Graal, 2004. p. 4-11.

HAMILTON, M. Sustainable literacies and the ecology of lifelong learning. In: HARRISON, R. R. F.; HANSON, A.; CLARKE, J. (Org.). Supporting lifelong learning. v. 1. London: Routledge, 2002. p. 176-187.

; BARTON, D.;IVANIC, R. (Org.). Worlds of literacy. Clevedon: Multilingual Matters, 1993.

HEATH, S. B.. Ways with words: Language, life, and work in communities and classrooms. Cambridge, England: Cambridge University Press, 1983.

\section{ILHA DO DESTERRO A JOURNAL OF ENGLISH LANGUAGE, LITERATURES IN ENGLISH AND CULTURAL STUDIES,}

Florianópolis, v. $\quad 69, \quad$ n. $\quad 3$, p. 1-8, set. 2016. ISSN 2175-8026. Disponível em:< https://periodicos.ufsc.br/index.php/desterro/issue/view/2360/showToc>. Acesso em: 31 fev. 2017.

KLEIMAN, A. (Org.). Os significados do letramento: uma nova perspectiva sobre a prática social da escrita. Campinas, SP: Mercado de Letras, 1995.

LEA, M. R; STREET, B. V. Student writing in higher education: an academic literacies approach. Studies in Higher Education, Colchester, v. 23. n. 2, p.157-173, 1998.

MARCUSCHI, L. A. Letramento e oralidade no contexto das práticas sociais e eventos comunicativos. In: CONGRESSO INTERNACIONAL DA ABRALIN, 2., Fortaleza, CE, 2001. Anais... Fortaleza, 2001.

OLIVEIRA, M. do S. Projetos: uma prática de letramento no cotidiano do professor de língua materna. In: OLIVEIRA, M. do S.; KLEIMAN, A. Letramentos múltiplos. Natal/RN: UDUFRN, 2008. p.93-118.

PEREIRA, M. V. A escrita acadêmica: do excessivo ao razoável. Revista Brasileira de Educação, Rio de Janeiro, v. 18, n. 52, p. 213 244, 2013.

POSSENTI, S. Notas sobre linguagem científica e linguagem comum. Cadernos Cedes, Campinas, v. XVII, n. 41, p. 9-24, 1997.

SANTOS, B. S. Introdução a uma ciência pós-moderna. Rio de Janeiro: Edições Graal, 1989.

SIGNORINI, I. Letramento e (in) flexibilidade comunicativa. In: KLEIMAN, Â. (Org.). Os significados do letramento. Campinas: Mercado de Letras, 1995. p.161-200. 
STREET, B.. Literacy in theory and practice. Cambridge: CUP, 1984.

TINOCO, G. A. Mundos de letramentos. In: OLIVEIRA, M.S.; KLEIMAN, A.B. Letramentos múltiplos: agentes, práticas, representações. Natal, RN: EDUFRN, 2008. p.63-89.

Recebido em 21/11/2016. Aceito em 31/03/2017. 